\title{
Comparative Study of Small Dose Bupivacaine-fentanyl vs. Normal Dose of Bupivacaine in Spinal Anaesthesia for Patient Above 60 Years Old Undergoing Surgery
}

\author{
Thaer Ali Hussein Al Akam¹, Emad Mohammad Hussein ${ }^{1}$ \\ ${ }^{1}$ FICMSA, Anaesthesiologist, Fellow of Iraqi Council of Medical Speciality, Aldewaniya Teaching Hospital, Iraq
}

\begin{abstract}
The purpose of the study was to compare small dose bupivacaine - fentanyl and normal dose of bupivacaine in spinal anaesthesia for patient above 60 years old undergoing femoral and tibial surgery 80 elderly patients of either sex belonging toASAI, II \& III undergoing elective orthopedic lower limb surgeries underspinal anaesthesia were studied in this prospective, randomized double blinded study. First group $A(n=40)$ wasgiven inj. Bupivacaine hyperbaric $3 \mathrm{ml}(15 \mathrm{mg})$ \& group B ( $\mathrm{n}=40)$ was given inj. Bupivacaine $(2 \mathrm{cc})+25 \mathrm{mcg}$ fentanyl Parameters like time for adequate level of analgesia (T9), peak sensory level reached,beginning of motor block to receed to L3-L4 level (modified bromage scale), how long sensory block continue and number of complications are noted in both groups result: The time of adequate level of sensory block to be started (T9) was longer for group Bthan group A. How long of sensory block to be started was slightly more for group A. the time of motor block continue to work was more in A than group B. It is concluded that subarachnoid block with $2 \mathrm{cc}$ bupivacaine $0.5 \% \mathrm{H}$ and $25 \mathrm{mcgfentanyl}$ is a more safer and better option for patient above 60 years of age undergoing femoral and tibial surgeries.
\end{abstract}

Keywords: Spinal anaesthesia, patient, bupivacaine-fentanyl, bupivacaine.

\section{Introduction}

Universally agreed that best type of anaesthesia for fracturefixationoftibiaandfemuresurgeryissubarachnoid block producing less post operative loss of memory and hallucination than general anaesthesia. ${ }^{1}$ However spinal block has got its own inherent complications, especially related to cardiovascularstability ${ }^{2}$. Perioperative hypotension may affect postoperative recovery and also the large number of coronary disease, put patient at risk of ischemia secondary to hypotension ${ }^{3}$. Vasopressor and IV fluids are used to treat or prevent hypotension. Another technique is byusing very low titrated dose of local anaesthetic but itmay not provide acceptable time for sufficient anaesthesia and better time for surgery. Studies have established that fentanyle and Marcaine anaesthetics administered together intrathecally have very strong synergestic analgesic effect, enhancing spinal blockade without affect the degree of sympathetic blockade ensuring better hemodynamicstability ${ }^{4}$. The purpose of this study was to COMPARE hemodynamic and sensory effect of small dose bupivacaine_fentanyl in regional anaesthesia versus ordinary dose of bupivacaine in patients undergoing surgical correction of lower limb tibial and femoral ${ }^{5}$.

\section{Materials and Method}

After approval of institutional ethical committee and informed concent 80 patients of ASA I,II, \& III with age $>50$ years of both sexes undergoing elective lower limb orthopedic surgeries were included in this double blindrandomized trial. Patients with history of allergy to localanesthetics, severe cardiac or respiratory diseases and uncontrolled hypertension were excluded. After routineand special investigations (if required) are done, patients were randomly allocated to group A (Bupivacaine-15mg,3ml) \& group B (Bupivacaine10mg, $2 \mathrm{ml}+25 \mathrm{mcg}$ [1 $\mathrm{ml}]$ fentanyl). Demographic data were comparable in age,height and duration of surgery (Table-1). Patients were fasted 8-10 hours and in operation theatre preloading with $8 \mathrm{ml} / \mathrm{kg}$ Ringer lactate done and standard monitorsapplied. From previous studies, low dose of bupivacaine and fentanyl was 
identified. Those studies are as below. Diana Fernander 2., Monterrat Rue et al (1996) $12.5 \mathrm{mg} 1$. Plus saline or 25 mcg fentanyl. Ben David, frankel et al (2000) 4mg bupivacaine plus3.20 Mcg fentanyl4. Atallah et al (2006) .Under full sterilized and antiseptic precautions lumbar spinal Block was done in sitting position in L3-L4 space by 22 Quincke needle both group were given respective drugs and sensory level of T6- T8 was achieved . patients were given oxygen by ventimask of 4 L/MINUTES .pulse rate, blood pressure, spo2 were measured every 5 minutes for first 20 minutes and then every 10 minutes for next 1 hour and then every hour for the next 24 hours postoperatively hypotension was defined as SBP $\leq 90$ or mean arterial BP30\% lower than baseline decline of greater than $30 \%$ from normal mean arterialpres sure which must treated with an incremental IV bolus of phenylephrine $50 \mathrm{Mic}$, Bradycardia defined as Heart Rate below 60 BPM must treated with IV Atropine other parameter like time for adequate level of analgesia peak sensory level reached, Time for Motor block to recede To L3-L4 level, duration of sensory block(Table-2) and incidence of complications likeNausea, vomiting, pruritus, sedation, shivering were assessed and compared .Motor block was assessed using modified Bromage scale 0 no paresis - full movement of lower limb

1-- Partial paresis - flex knees and ankles

2-- Partial paresis - flex ankles .

3-- Full paresis - no movement

Sedation status was assessed using

0 -Awake and alert

1-- Respond to voice

2-- Respond to painful stimuli

3-- No response

\section{Results}

The study was done in double blinded, prospective randomized manner in 80 patients in al diwaniya teaching hospital and al furat private hospital scheduled to undergo elective orthopedic lower limb surgeries under spinal anaesthesia . the demographic data (age, weight . sex, and ASA grading) were comparable and statically non significant (table 1) ALL surgeries was lasted from 110 to 180 minutes equal distribution of mens and womens in both groups was done and most of them were ASA 11 - III students T-test was used f0r statistical Analysis .

- The BEGINNING of adequate level of sensory block (T9) was little late for group B $(128+/-8 \mathrm{sec})$ than $\mathrm{A}(95+/-10 \mathrm{sec})$ and was statically significant (table 2)

- HOW long motor block was continued in group A1 $(162+/-7 \mathrm{~min})$ comparing to B2 $(129+/-9)$ and was statistically significant .

- Lower pulse rate less drop in blood pressure was noted in group B2 than group A1, thus there is better haemodynamic stability in group B2

- Incidence of drop in BP and use of vas0press0rs WAS much larger in group A1 and was found to be statically significant

- Latency of sensory block was slightly more for group A1 but was not found to statically significant

- Boutes of bradycardia 0r pruritus was common in group B2.

- No one of the patients in both groups had regergutation $0 \mathrm{r}$ vomiting $0 \mathrm{r}$ respiratory depression .

- Shivering was higher in group A

- RASS score was used to assess sedation intraoperative and postoperative. (rantigon agitated sedative score)

\section{Discussion}

Maintenance of body physiology as near normal as possible during anaesthesia is one of the primary goals of anaesthesiologist . Marked hemodynamic derangement are often seen following subarachnoid block especially in trauma and elderly patients. Neuraxial opoids are not associated with sympathetic nervous system denervation, muscle power weakness or loss of speech . they predominantly act at the MU receptor present in substantiagelatinosa of spinal cord to exert its synergistic effect more specifically for visceral pain. The recommended level of regional anaesthesia for lower limb surgery is $\mathrm{T} 9$. standard recommended dose of $0.5 \%$ hyperbaric bupivacaine is $3 \mathrm{cc}(15 \mathrm{mg}) \mathrm{In}$ our present study, we have added $25 \mathrm{Mcg}$ fentanyl, ahighly lipophilic opoid to lower doses of $0.5 \%$ bupivacaine hyperbaric and COMPARED hemodynamic parameters like blood pressure, heart rate changes, side effects of fentanyl and motor and sensory profiles of block. 
In our study 16 patient of group A developed hypotension and needed vasopressors compared 4 patients of group B2 . these finding are in agreement with finding of Ben David et al (2000), Ben David, Frankel (2000), Matyr (2001). There were high increase in the beginning of adequate block in group B2 $(128+-/ 8.3 \mathrm{sec})$ as compared to group A1 $(95+-/ 10.32 \mathrm{sec})$. Addition of fentanyl reduces the $\mathrm{PH}$ of hyperbaric bupivacaine this may be reason for delay in onset of adequate block (table 2) The total duration of sensory block for group A was $227.6+/-9.8$ min while group B was $211.5+/-14.2$ min . the difference between two groups were statically insignificant as per Boucher et al (2001) and Rajesh Mahayan V K Grover et al (2005) addition of fentanyl enhances duration of sensory block in which dose of Bupivacaine $-\mathrm{H}$ was same . But in our study dose of
Bupivacaine in fentanyl group is much lower which can be the reas 0 n for slightly 10 wer duration of sensory block

MOTOR BLOCKED LAST LONGER in group A1 than group B2 and none of the patients required any supplementary anaesthetic interventions during surgery

There was no incidence of sedation or respiratory depression in 2 groups Fentanyl abolishes shivering by central mechanism in group B .pruritus is most c0mmon side effect of intrathecal opioid in our study 4 among 40 in group B had pruritus which was treated by ondansetron . Nausea and regurgitation were not seen in any 0 these gr0ups . adjuvant drug like fentanyl reduces the $\mathrm{PH}$ of hyperbaric bupivacaine. It may be the reason for the delay in onset of adequate block .

Table 1. Data were comparable in age, height and duration of surgery

\begin{tabular}{|c|c|c|}
\hline Group B2 & Group A1 & Parameters \\
\hline $68+-7$ & $65+-6$ & Age \\
\hline $163+-5.5$ & $164+-5.8$ & Height \\
\hline $128+/-32$ & $135+-30$ & Duration of surgery (min) \\
\hline $25: 15$ & $25: 15$ & Male $:$ Female \\
\hline $24: 16$ & $25: 15$ & ASA Grade 11: 111 \\
\hline
\end{tabular}

Table 2: Characteristics of spinal block.

\begin{tabular}{|c|c|c|}
\hline Group B & Group A & \\
\hline $127+/-7.3$ & $96+/-10$ & Time of onset of adequate block $-\mathrm{T} 10(\mathrm{sec})$ \\
\hline $129+/-9$ & $163+/-7$ & Duration of motor block (min) \\
\hline $211.5+/-14.5$ & $227.6+/-9$ & Duration of sensory block (min) \\
\hline
\end{tabular}

Table 3. Complications: Group A and Group B

\begin{tabular}{|c|c|c|}
\hline Group B & Group A & \\
\hline $4(10 \%)$ & $16(40 \%)$ & Hypotension \\
\hline $2.4(6 \%)$ & $1(3 \%)$ & Bradycardia \\
\hline $4(10 \%)$ & 0 & Pruritus \\
\hline 0 & 0 & Sedation \\
\hline 0 & 0 & Nausea and regurgitation \\
\hline 0 & $4(10 \%)$ & Tremors \\
\hline 0 & 0 & Total spinal \\
\hline
\end{tabular}




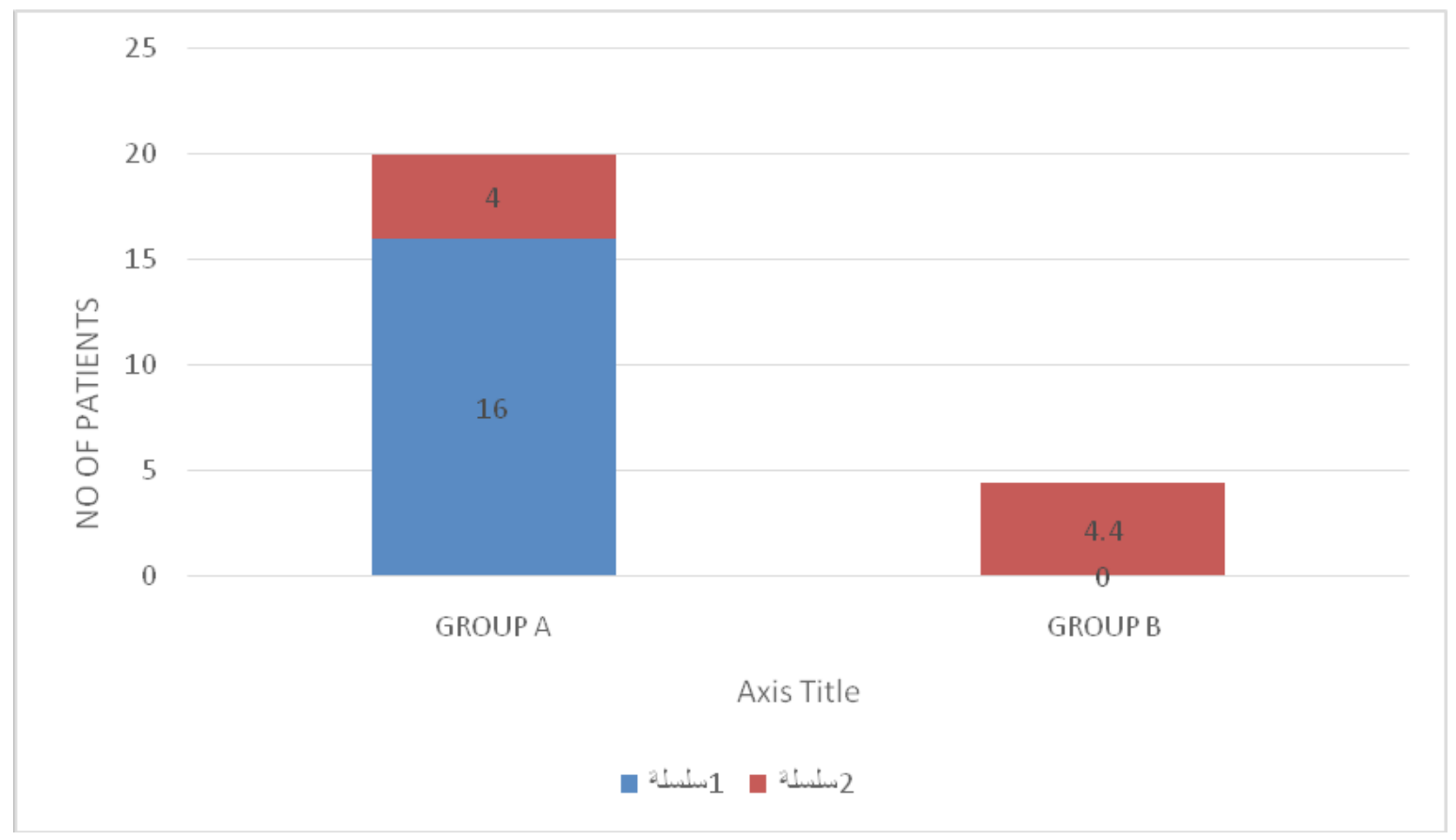

Figure 1. VASOPRESSORS Used

\section{Conclusion}

From current study it was concluded that subarachnoid block with 2 cc bupivacaine $0.5 \% \mathrm{H}$ and $25 \mathrm{Mcg}$ fentanyl is more safer study, both in terms of maintaininghemodynamic stability and lower incidence ofComplications with0ut C0mpr0mising the surgicalcondition for patients undergoing femoral and tibial surgeries . $\mathrm{B}+\mathrm{F}$ can be a safer altconventional dose of bupivacaine, which can be reducedafter adding Fentanyl in low dose bupivacaine, after completing this study, we will study for other doses .

Financial Disclosure: There is no financial disclosure.

Conflict of Interest: None to declare.

Ethical Clearance: All experimental protocols were approved under the Aldewaniya teaching hospital and all experiments were carried out in accordance with approved guidelines.

\section{References}

1. Shiva K. Current Concepts in neuraxial administration of opioids and non-opioids- An overview and future perspectives. Indian journal of Anaesthesia. 2004; 13-24.
2. Atallah A. Intrathecal low dose bupivacaine and fentanyl for PCNL. Acta Anaesthesiology Scandinavia. 2006; 50(7).

3. Ben-David B, Frankel R. Minidose bupivacaine fentanylsubarachnoid block for surgical repair of hip fracture in aged. Anaesthsia 93(5): 1365, 2000.

4. David M, Guevich A. Spinal anaesthesia with bupivacaine and fentanyl in Geriatric patients. Anaesth Analg. 83:Am. J. Hosp. Pharm. 49: 515518, 1992.

5. Edward M. Geraitric Anaesthesia, Clinicalanaesthesiology, 3 edn 2002; 875-879

6. Goel S. Intrathecal fentanyl added t0 intrathecal bupivacaine. For day care surgery. Eur0pean j0urnal of Anaesthesia. 2003; 20(4): 97.

7. Gurkan Y, Canatay H, zdamar D, Solak M, Toker K. Spinalanaesthesia for arthroscopic knee surgery. Acta Anaesthesiology Scand. 2004; 48(4): 513-17.

8. PriebeHJ. The aged cardiovascular risk patient. BJA 2000; 85(50): 763

9. Hamber EA, Viscomi CM: Intrathecal lipophilic opioids asaadjuncts to surgical spinal anaesthesia. Reg. Anaesth. Pain med. 1999; 24(30: 255-263.

10. Comparison of minidose of fentanyl and conventional dose oflidocaine in spinal anaesthesia. Anaesthesia Analgesia 2000; 91(4). 
11. Ben B, Miller G, Gavriel R, Gurevitch A. Low dosebupivacaine fentanyl for spinal anaesthesia for cesariandeliveries...Pain Medicine. 2000; 25(3) : 235-239.

12. BertilL, Mats B. Intradural and extraduralanalgesia: Grey \& Nunn's. General anaesthesia 5 edition, Uttang et al (eds). 2000 .

13. Biley PL, Egan TD, Stanely TH: Intravenous opioid anaesthetics:in Ronald D Miller Anaesthesia 5 edition 2000, Churchil Livingston. 2000; 278-79.

14. Boucher C, Girard M, Grenier V, Bergeron L, LE Truong $\mathrm{H}$ :Intrathecal fentanyl dose not modify the duration of procaineblock: Canadian journal of anaesthesia.2001; 48(5): 466-469.

15. Bruce B, Eric $S$, Hilton L. Intrathecalfentanyl with small dose of dilute bupivacaine : better anaesthesia without prolonging recovery: Anaesthesia Analgesia 1979; 85: 560-65,
16. Butterworth JF, Srichartz GR: Molecular mechanism of localanaesthesia-A Review: Anaesthesiology. 1997; 86:525-53

17. Buvanendran A, Mccarthy RJ: Anaesthesia Analgesia 2002; 95(3):616-

18. Carl C, Hugh JR. Pain management in clinical Anaesthesiologyedn, Edward Morgan G Jr et al (ed.) Lange, McGraw Hill. 1997; 253-279.

19. Catherine O, Hunt J. Peri-operative analgesia with subarachnoid fentanyl-bupivacaine for caserian delivery. Anesthesiology 1989; 71: 535-540.

20. Chow T C, Cho PH. The influence of small dose of intrathecalfentanyobn shivering during TURP under spinal asnaesthesia. Acta Anaesthesiology Scandinavia. 1994; 32(3): 165-70. 